\section{A NEW PIAN OF TREATMENT FOR PNEUMONIA.}

Read in the Section of the Practice of Medicine, Materia Medica and Physiology, at the Fortieth Annual Meeting of the American Medical Association, June, I880.

BY G. R. MAR'TINE, M.D., GLEN'S FALLS, N. Y.

Every new theory is at first more or less ridiculed by the incredulous class, and the number of those incredulously inclined is unfortunately as large to-day as when Harvey discovered the circulation of the blood, or Jenner promulgated the boon of vaccination. Hence no surprise will be created should this new plan of treatment for pneumonia be derided, or even denounced in terms more vigorous than elegant. But still among you all there may be one patient investigator searching for truth, who will give this new theory a practical test ; and if so, he will be induced to make a second trial; and when he ascertains that substantially it never fails, it will then become his fixed, permanent and unalterable practice in the treatment of pneumonia.

No attempt will be made in this paper to enter into an extended research or exhaustive analysis relative to the cause, pathology or results of pneumonia, or to discuss at length its different forms and phases. It is simply to a new plan of treatment toward which your attention is called, and to this point all efforts will be directed. Almost every known plan has been adopted in the treatment of pneumonia, and the new remedies have been eagerly sought after ; first one and then another has played its rôle on pneumonia's stage with but indifferent success. Bleeding, vomiting, sweating, blistering, poulticing, depleting, stimulating, all local and all general plans of treatment have been faithfully and persistently carried out with marked thoroughness and perseverance; and yet to-day, after all the advancement made in the science of medicine, pneumonia, though a curable disease, stands second only on the roll-call of death. Shall we continue longer in these old ruts, with this appalling death-rate staring us in the face at every step, or shall we seek out a new and more rational plan of treatment?

The first abnormal symptom observed after the premonitory chill has warned us of pneumonia's approach, is the quickening of the pulse and the consequent increased flow of arterial blood. Now, if we could take a microscopic view of the minute arterial ramifications in the lung structure, we would discern in response to the law of causation, a distention of caliber in the arterial vessels in order to accommodate the augmented flow of arterial blood; and if we could then cast a glance at the veins, we would observe the plasma-layer rapidly filling with multitudinous white corpuscles, and the walls of the veins irritated by the friction of increased circulation would exhibit here and there white corpuscles adhering to their tenacious sides, and finally penetrating their walls. A glance at the capillaries would show not only the white but also the red blood-corpuscles forcing their way through the overstrained capillary walls, until the surroundings became engorged by their extravasation, and the initiatory work of hepatization had commenced, for the comparatively large size of pulmonary capillaries, together with the fact of their not being supplied with raso-motor nerves, render them easily dilatable under increased arterial pressure. Now what are we to do at this stage of the disease in order to hold in check this increased flow of blood to the lungs, which, if unrestrained, is sure to end in consolidation and death. Reducing the temperature will not accomplish the work. Reduction of temperature does not save in pneumonia as in idiopathic fevers. To what plan, then, shall we resort in this exciting emergency to save the patient from being suffocated by his own blood? Before an answer is given, allow me to use a simile: Should some mischievous hand hoist the gate of an immense reservoir, located at an elevation a thousand feet above this city, and the maddened waters, fiendish with the power of innundation, should sweep through your streets, undermining block after block, and strangling all life within reach of its destructive course, would you not intuitively cry out, shut down the headgate and save the city?

When the maddened blood, fired by the lash of inflammation, rushes wildly through the channels of life, extruding with demoniacial force through the very walls of the blood vessels the bloodcorpuscles and threatening to strangle out the life of the unfortunate victim, intuitively I cry out, shut down not the head-gate but the heartgate and thus save the suffocating patient who helplessly looks to you for rescue. Say to the wildly pulsating heart, so far or so fast shalt thou go, and no faster, and continue to hold the heart's action under absolute subjection until the crisis is past and the life of the patient is saved. (This crisis is usually reached about the seventh day after the chill.) This is not only what should be done, but what must be done, in order to ward off death. Here is where the new plan saves life. You will naturally ask if this new plan is intricate or difficult of adoption, or if it be so extended or complicated as to render it practically inoperative in the hands of the busy practitioner. The answer is, no. The whole method can be given in five words, viz: Hold the pulse below eighty. Keep your fever thermometer in your pocket; it is of little or no use in pneumonia. Death does not result from high temperature in pneumonia, but from high arterial action, resulting extravasation and consolidation and consequent heart failure. The physician who, dallying with his fever thermometer, endeavors to cure 
pneumonia by reduction of temperature, will make about as much headway and will be about as successful as he would in trying to eat soup with a peg-awl. You may ask with what remedies do you hold the pulse at this point. While veratrum viride seems to have served me best, possibly there are other arterial sedatives which in the hands of others may act as well. It has heretofore been the practice of medical writers to name the medicines to be used in the treatment of such and such diseases, but in the light of the present day it would be well to drop this antiquated custom and adopt a new method by stating the indications to be fulfilled, the dangers to be avoided, the vantage ground to be gained, the favorable signs to be sought for, and the unfavorable symptoms to be controlled, the main points to be attained, and the results to be expected in the successful management and treatment of any disease, and then allow the attending physician to select such remedial agents as he may choose from among those possessing his confidence after long experience in their use.

In pursuance of this course no radical line is drawn or arbitrary rule laid down as to the remedial agents used, provided they are successful in accomplishing the work of holding the pulse below eighty if in adults, or if children, from one hundred to one hundred and twenty. This point attained and with persistent vigilance maintained, no further trouble need be apprehended, for with the pulse at or below eighty, there will be no extravasation, if no extravasation there will be no consolidation, if no consolidation there will be no hepatization, and if no hepatization there can be no suppuration, mortification or death. Hence pneumonia, by this plan, can be robbed of all its terrors.

But the inquiry may be made: What is there in this plan to provide against heart failure, a condition so greatly to be dreaded, and the reply is : It is far better to avert a calamity than to provide for one. No censure is due the captain of a man-of-war who thickly covers his deck with sawdust to prevent slipping when blood shall flow freely; but a higher meed of praise is accorded that captain who so carefully erects defenses, so skillfully plans the attack, so closely watches the progress of the battle, and so adroitly conducts the fight that but little blood need flow.

So in this new plan of treatment for pneumonia, but little blood will flow if the pulse be kept below eighty. If no blood be extravasated no consolidation takes place, and if no obstruction from consolidation exist, and the heart's muscular labor be not consequently increased by its continued efforts to force the blood through pulmonary channels already clogged and blocked, and provided further that the heart is restrained and thus relieved from the fatiguing additional Aabor of 2,000 to 4,000 contractions per hour during the seven days preceding pneumonia's crisis, heart failure in uncomplicated pneumonia would be a thing impossible.

DR. H. A. HARE said that the use of veratrum viride was old and very useful, but that a great mistake is made in saying "use cardiac sedatives in pneumonia" without recognizing the fact that they are to be used in the first stage before congestion has gone on to consolidation. The man who gives such drugs at the middle or end of an attack of pneumonia might as well stab his patient. Digitalis is to be used at such times. As to the lethal results of veratrum viride let me say that very few cases of death are on record, owing to the vomiting which is brought on very early by the alkaloid veratroidia and an emetic resin. It is certainly the safest cardiac sedative.

DR. I. E. ATKInson, of Baltimore, objected to the claim that the use of veratrum viride in the treatment was new; it had been many years under trial and had not received general acceptance. He called attention to the fact that Dr. Martine's graphic description of "drowning in their own blood" as the mode of death in many cases of croupous pneumonia could not be justified; that frequently the cause of death was in the failing heart action, a condition to which we could not look for benefits from heart depressants. He would not be much impressed by the successful results of giving veratrum viride in the croupous pneumonia of children, since this disorder usually will recover under any ordinary treatment.

Dr. Cronyn said: Dr. Martine's new mode of curing preumonia is not at all new. Bleeding and rasher emetics were the methods of our forefathers to attain the results pointed out by the doctor. We know very well that about forty years ago a complete revolution in the treatment of diseases generally, and pneumonia, was made the basis of argument particularly. I hold, sir, that every case of inflammation of the lungs must be treated upon its own merits, taking into consideration the constitutional condition. The peculiarities of such cases and the remedies are easily determined.

Dr. C. O. Probst, secretary of the Ohio State Board of Health, is sending out circulars to the mayors and councils of all the cities of that State that have not formed boards of health, urging them to do so. The law requires all towns having a population of five hundred or more to establish these boards. The circular says: "One of our smaller villages, which neglected its duty in this matter, is now paying the penalty in a severe epidemic which a board of health might have prevented."'-Sanitary News, Sept. 7, I 889. 